\title{
Two criteria of oral glucose tolerance test to diagnose gestational diabetes mellitus
}

\author{
Dodrigo Dias Nunes, \\ (iD) Mayara Eloisa Flôres ${ }^{1}$ \\ (iD) Mayara Seemann ${ }^{1}$ \\ (iD) Eliane Traebert $\mathbf{1}^{1,2}$ \\ (D) Jefferson Traebert ${ }^{1,2}$
}

1. Escola de Medicina. Universidade do Sul de Santa Catarina, Palhoça, SC, Brasil. 2. Programa de Pós Graduação em Ciência da Saúde. Universidade do Sul de Santa Catarina, Palhoça, SC, Brasil.

http://dx.doi.org/10.1590/1806-9282.66.2.139

\section{SUMMARY}

OBJECTIVE: To evaluate two different criteria, one or two cut-off values, of oral glucose tolerance test with $75 \mathrm{~g}$ of glucose for the diagnosis of gestational diabetes mellitus.

METHODS: A cross-sectional study involving 120 records of pregnant women who received prenatal care at the service of a Brazilian university was carried out. Bivariate analysis of obstetric and perinatal outcomes was performed using the chi-square test.

RESULTS: Considering criterion I, 12.5\% of patients were diagnosed with gestational diabetes mellitus. Patients were 3.57 times more likely to have a large fetus for the gestational age at birth $(p=0.038)$. Using criterion II, gestational diabetes mellitus was diagnosed in $5.8 \%$ of patients, macrosomia was 7.73 times more likely to be found in the presence of gestational diabetes mellitus ( $p=0.004)$, and a large fetus for the gestational age at birth was 8.17 times more likely $(p=0.004)$.

CONCLUSIONS: There was a difference in the prevalence of gestational diabetes mellitus between the two criteria analyzed. The new criterion proposed increased prevalence.

KEYWORDS: Diabetes, gestational. Diagnostic techniques and procedures. Glucose tolerance test. Perinatal care.

\section{INTRODUCTION}

Gestational diabetes mellitus (GDM) is characterized by a carbohydrate intolerance with onset or diagnosed during pregnancy ${ }^{1}$. The stress caused by pregnancy, with other genetic and/or nutritional factors, are the main causes of GDM due to the increase of insulin counter-regulatory hormones' ${ }^{1}$.

In addition to clinical and obstetric complications for the patient, during pregnancy and at birth, children from pregnant women with GDM present a higher risk of neonatal hypoglycemia, macrosomia, polyhydramnios, abnormal presentation, birth injury, malformation, and perinatal death ${ }^{1,2}$. Prenatal exposure to GDM is a predictor of glucose intolerance and obesity in adolescence. However, associations with the long-term effects of GDM on infants continue to be investigated ${ }^{3}$. Moreover, GDM is a predisposing factor for the development of Type 2 diabetes mellitus (DM) 5 years after pregnancy among those women ${ }^{4}$.

The incidence of GDM varies depending on the population studied and the different diagnostic criteria'. The overall prevalence of GDM is $3-5 \%$, reaching up to $18 \%$. In Brasil, the estimated prevalence ranges from 
$2.4 \%$ to $7.2 \%^{5}$. In the United States, the disease affects $1.4 \%$ to $2.8 \%$ of women at low risk, and $3.3 \%$ to $6.1 \%$ of women present some risk factor ${ }^{6}$. A review published covering the last 10 years on the evolution of GDM prevalence suggests that it will increase significantly ${ }^{6}$.

Therefore, GDM is a common obstetric complication, and its prevention is a public health priority ${ }^{6}$. There are many options for screening and diagnosing this disease, and the disagreement of the methodology applied by different services reflects on the results of different studies. This incongruity leads to diversified protocols of investigation of $\mathrm{GDM}^{7-9}$. Although not diagnosed with GDM, many patients have elevated blood glucose levels, which would make them possible subjects with diabetes according to some other investigation criterion ${ }^{9}$. This is a problem that requires further elucidation. However, what appears to be a consensus among the different criteria used is the association of GDM with its risk factors ${ }^{1,5,7,9}$.

The Hyperglycemia Adverse Pregnancy Outcomes (HAPO) research group, conducted a study on the adverse results of increased maternal blood glucose during pregnancy. It was demonstrated that high blood sugar levels lead to increased frequency of newborns (NB) with birth weight above $90^{\text {th }}$ percentile of the expected for the gestational age (GA) and increased incidence of cesarean delivery and neonatal hypoglycemia. It also suggests that maternal hyperglycemia, not diagnosed as GDM, is associated with neonatal abdominal fat deposition, mediated by fetal insulin production $^{3,4}$.

Women who underwent proper treatment for GDM had a reduced number of macrosomic fetuses. However, some authors claim that there is a modest benefit in identifying and treating women with GDM, when related to long-term complications developed over time, such as Type 2 DM and obesity ${ }^{10-12}$.

The American Diabetes Association (ADA) defines GDM as diabetes diagnosed in the second or third trimester of pregnancy that was not clearly overt diabetes prior to gestation ${ }^{13}$. Getting a pattern on issues concerning screening time, diagnostic tests, and the appropriate glycemic cut-offs that should be used to define GDM is still a problem ${ }^{13-15}$.

Recently, the International Association of Diabetes and Pregnancy Study Groups (IADPSG), in accordance with the American Diabetes Association (ADA), published a consensus derived from the HAPO study. The goal was to find the exact cut-off point linking maternal hyperglycemia with adverse perinatal events, which would allow for the possibility of revising the diagnostic criteria for GDM ${ }^{14-16}$. Such consensus suggests that all pregnant women, regardless of the existence of risk factors for the development of GDM, should undergo an oral glucose tolerance test (OGTT) with dosages of fasting plasma glucose (FPG), 1-h and 2-h after ingestion of $75 \mathrm{~g}$ of glucose, between 24-28 weeks of pregnancy. It proposed cut-off points at 92 $\mathrm{mg} / \mathrm{dl}, 180 \mathrm{mg} / \mathrm{dl}$, and 153mg/dl, respectively ${ }^{15}$. According to these criteria, if at least one of these values is equal to or above those limits, GDM will be diagnosed. The Brazilian Federation of Gynecology and Obstetrics Association (FEBRASGO), supported by the Brazilian Diabetes Society (SBD), suggested the use of another criterion, with the same OGTT of $75 \mathrm{~g}$ of glucose, measured between 24-28 weeks. GDM would only be present if two values were equal or higher than $95 \mathrm{mg} / \mathrm{dl}$, $180 \mathrm{mg} / \mathrm{dl}$, and $155 \mathrm{mg} / \mathrm{dl}$, respectively ${ }^{17}$.

Other screening methods are used worldwide. The Canadian Diabetes Association (CDA) recommends all women to be screened with a 1-h glucose measurement after a 50-g oral glucose load between 24 and 28 weeks of gestation, followed by the 2-h 75-g OGTT if the threshold has been surpassed ${ }^{18}$. This two-steps approach, commonly used in the USA, is supported by the American College of Obstetricians and Gynecologists (ACOG) ${ }^{\mathbf{1 9}}$ and recommended by the National Institutes of Health $(\mathrm{NIH})^{20}$. Overall, the one-step approach should be preferred due to its simplicity of execution, greater patient adherence, accuracy in the diagnosis of GDM, and closeness to the international consensus $^{15}$. The International Diabetes Federation (IDF) addresses some attention to this aspect by suggesting that selective screening should be considered only in particular epidemiological and clinical conditions, and local cost-effectiveness ${ }^{21}$.

As noted, there is no consensus on the best method for screening and diagnosing GDM. Apparently, the proposal advocated by some entities (FEBRASGO/SBD) is that if fewer cases of GDM are diagnosed, fewer treatments would be carried out and, consequently, worse outcomes could emerge. The elucidation of the best 2-h 75-g OGTT diagnostic criteria for GDM may help define adequate prenatal care protocols, minimizing the risks for pregnant women and their children. Therefore, this study aims to evaluate the difference in GDM prevalence with two different 2-h 75-g OGTT criteria and the difference between the obstetric and perinatal outcomes in cases where there is a disagreement between the methods. 


\section{METHODS}

A cohort study was carried out to test the association between obstetric and neonatal outcomes with two different criteria to diagnose GDM. All records of pregnant patients who consulted at the Gynecology and Obstetrics Ambulatory at the Universidade do Sul de Santa Catarina (UNISUL) and delivered their babies at the Regional Hospital de São José, both institutions located in the Metropolitan area of Florianópolis/SC, Brasil, for a one-year period. Those who presented $75 \mathrm{~g}$ glucose OGTT at 24-28 weeks of pregnancy were included. Women with Types 1 or 2 DM prior to pregnancy were excluded, once the screening protocol would not be performed on them.

The Ethics Committee on Human Research of UNISUL approved this study under protocol number 12.094.4.01.III. All the procedures were explained in detail to the participants, and informed consent was signed.

As the incidence of GDM was uncertain, the sample size was calculated based on the Pregnancy Risk Assessment Monitoring System (PRAMS) ${ }^{22}$ with a range from $1 \%$ to $25 \%$, depending on the ethnicity and diagnostic criteria used. Therefore, using a $25 \%$ positive exposure rate, a confidence level of 95\% (error type I = 5\%), a power of $80 \%$ (error type II $=20 \%$ ), and an equal non-exposure and exposure rate, a minimum sample size of 118 pregnant women was estimated. After analyzing the medical records, it was noted that 120 patients received both prenatal and delivery care. The outcomes that were considered to be compared with GDM diagnoses were macrosomia, polyhydramnios, NB weight according to gestational age at birth, fetal abdominal circumference (FAC), and type of delivery.

Outpatient medical records gathered information about the risk factors for GDM, laboratory values of FPG and OGTT, presence of polyhydramnios, and measurement of the fetal abdominal circumference. The body mass index (BMI) was calculated based on the anthropometric data on the first prenatal visit (weight/ height ${ }^{2}$ ). The measurement of FAC was obtained from the third-trimester ultrasound (34-36 weeks) and categorized with the Hadlock table for FAC ${ }^{23}$.

The hospital records offered information concerning the presence of macrosomia, NB weight according to gestational age at birth, and type of delivery ${ }^{24}$. NB with a weight greater than or equal to $4 \mathrm{~kg}$ were considered macrosomic ${ }^{18,19}$. NB with weight below the $5^{\text {th }}$ percentile, between the $5^{\text {th }}$ and $95^{\text {th }}$ percentile, and above the $90^{\text {th }}$ percentile expected for gestational age were classified as small, appropriate or large, respectively, and according to Hadlock table for estimated fetal weigh ${ }^{25}$.

The gestational age was calculated by the reliable last menstrual period and/or ultrasound in the first trimester of pregnancy. When there was disagreement between the two parameters, the highest gestational age was considered.

The investigation of GDM during prenatal care is a routine procedure in this service, performed in all patients with no previous diagnosis of type 1 and Type $2 \mathrm{DM}$. The OGTT is performed on all patients with FPG blood tests higher than $85 \mathrm{mg} / \mathrm{dl}$ in the first trimester of pregnancy and with any risk factor for GDM. The OGTT is carried out with $75 \mathrm{~g}$ of glucose, between 24-28 weeks of gestation, following 3 stages (FPG, 1-h, and 2-h after glucose intake). The cut-off points are 95 $\mathrm{mg} / \mathrm{dl}, 180 \mathrm{mg} / \mathrm{dl}$, and $155 \mathrm{mg} / \mathrm{dl}$ ), respectively. If two or more results are equal to or greater than the cut-off point, GDM is considered as diagnosed. According to this protocol, after diagnosed with GDM, the patient is referred for appropriate treatment and monitoring.

Data from the OGTT were evaluated and interpreted as two diagnostic criteria for GDM. Criterion I (IADPSG / ADA) 14-16: GDM was diagnosed when at least one value was equal to or greater than the cut-off for FPG (92 mg/dl), 1-h (180 mg/dl), and 2-h (153 mg/dL) OGTT, respectively. Criterion II (FEBRASGO / SBD) [17]: GDM was diagnosed when at least two or more values were equal to or greater than the cut-off for FPG (95 mg/dl), 1-h (180 mg/dl), and 2-h (155 mg/dL) OGTT, respectively. Posteriorly, the outcomes were compared to the presence of GDM according to both criteria, and to those patients diagnosed with GDM under criterion I but not under criterion II (Figure 1).

Statistical analysis was performed using SPSS version 18.0. Qualitative variables were described in absolute and relative frequencies, and quantitative variables were categorized for further bivariate analysis. The chi-square was used to test the homogeneity of proportions. The significance level was $\mathrm{p}<0.05$. Odds ratios with $95 \%$ confidence intervals (95\% CI) were estimated.

\section{RESULTS}

In the study population, the mean age was 27.3 years ( \pm 7.0$)$. Regarding the skin color, $86.7 \%$ of patients were white, $9.2 \%$ were black, and the remaining $7.4 \%$ 
were of other ethnicities. None of the patients reported being illiterate, $32.5 \%$ completed high school, and 2.6\% had joined college.

The analysis of the risk factors for GDM showed $62.5 \%$ of patients aged 25 years old or more, $54.2 \%$ with $\mathrm{BMI} \geq 25 \mathrm{~kg} / \mathrm{m}^{2}, 29.2 \%$ with family history of DM, $0.8 \%$ used corticoid, $0.8 \%$ used thiazide diuretic, $1.7 \%$ with polycystic ovarian syndrome, $4.2 \%$ with systemic arterial hypertension, $30.0 \%$ with excessive weight gain, and $4.2 \%$ with preeclampsia. About the risk factors during a previous pregnancy, 3.3\% of the patients had had GDM, 3.3\% had had macrosomia, 18.3\% had experienced fetal or neonatal death, and $6.7 \%$ had undergone preterm labor.

Considering criterion I, $12.5 \%$ of patients would be diagnosed with GDM. Under this criterion, large fetus for the gestational age at birth were 3.57 times (95\% CI 1.01-12.59) more likely in patients with GDM $(\mathrm{p}=0.038)$ (Table 1).

Using criterion II, GDM was diagnosed in $5.8 \%$ of the patients. These patients belonged to the treated group, according to the service protocol. Under this criterion, macrosomia was 7.73 times (95\% CI 1.5139.49) more likely in the presence of GDM ( $\mathrm{p}=0.004)$, and large fetus for the gestational age at birth were 8.17 times (95\% CI 1.58-42.32) more likely in these patients ( $\mathrm{p}=0.004)$ (Table 1).

After sorting out patients diagnosed as GDM by criterion I, but not by criterion II, no outcome associated with the presence of GDM was found (Table 1).

TABLE 1. ASSOCIATION BETWEEN OBSTETRIC AND PERINATAL CHARACTERISTICS AND THE PRESENCE OF GDM BY CRITERION I (IADPSG ${ }^{\varepsilon} /$ ADA $^{*}$ ), CRITERION II (FEBRASGO / SBD $)^{\square}$ AND CRITERION I (IADPSG ${ }^{\varepsilon}$ / ADA*) BUT NOT BY CRITERION II (FEBRASGO / SBD $)$. PALHOÇA, SC, BRASIL $(N=120)$.

\begin{tabular}{|c|c|c|c|c|c|c|c|c|c|c|c|c|c|c|c|}
\hline \multirow{3}{*}{$\begin{array}{l}\text { Obstetric } \\
\text { and perinatal } \\
\text { character- } \\
\text { istics }\end{array}$} & \multicolumn{3}{|c|}{$\mathrm{GDM}^{*}$ by Criterion I } & \multirow[t]{3}{*}{$p$-value } & \multirow{3}{*}{$\begin{array}{l}\text { OR† (Cl } \\
95 \%)\end{array}$} & \multicolumn{3}{|c|}{$\mathrm{GDM}^{*}$ by Criterion II } & \multirow[t]{3}{*}{$p$-value } & \multirow{3}{*}{$\begin{array}{l}\text { OR† (Cl } \\
95 \%)\end{array}$} & \multicolumn{3}{|c|}{$\mathrm{GDM}^{\star}$ by Criterion I - Criterion II } & \multirow[t]{3}{*}{$\mathrm{p}$-value } & \multirow{3}{*}{$\begin{array}{l}\text { OR† (Cl } \\
95 \%)\end{array}$} \\
\hline & Yes & No & Total & & & Yes & No & Total & & & Yes & No & Total & & \\
\hline & $n(\%)$ & $\mathrm{n}(\%)$ & $n(\%)$ & & & $\mathrm{n}(\%)$ & $n(\%)$ & $n(\%)$ & & & $n(\%)$ & $n(\%)$ & $n(\%)$ & & \\
\hline \multicolumn{16}{|l|}{ Macrosomia } \\
\hline Yes & $5(38.5)$ & $8(61.5)$ & $\begin{array}{l}13 \\
(10.8)\end{array}$ & 0,061 & $\begin{array}{l}3.30 \\
(0.96- \\
11.34) \\
\end{array}$ & $3(23.1)$ & $\begin{array}{l}10 \\
(76.9)\end{array}$ & $\begin{array}{l}13 \\
(10.8)\end{array}$ & 0.004 & $\begin{array}{l}7.73(1.51- \\
39.49)\end{array}$ & $2(20.0)$ & $\begin{array}{l}8 \\
(80.0)\end{array}$ & $10(8.8)$ & 0.512 & $\begin{array}{l}1.73(0.33- \\
9.06)\end{array}$ \\
\hline No & $\begin{array}{l}17 \\
(15.9)\end{array}$ & $\begin{array}{l}90 \\
(84.1)\end{array}$ & $\begin{array}{l}107 \\
(89.2)\end{array}$ & & 1.00 & $4(3.7)$ & $\begin{array}{l}103 \\
(96.3) \\
\end{array}$ & $\begin{array}{l}107 \\
(89.2)\end{array}$ & & 1.00 & $\begin{array}{l}13 \\
(12.6)\end{array}$ & $\begin{array}{l}90 \\
(87.4)\end{array}$ & $103(91.2)$ & & 1.00 \\
\hline \multicolumn{16}{|c|}{ Polyhydramnios } \\
\hline Yes & - & $\begin{array}{l}1 \\
(100.0)\end{array}$ & $1(0.8)$ & 0,643 & \begin{tabular}{|l|}
2.21 \\
$(0.07-$ \\
$67.79)$ \\
\end{tabular} & - & $\begin{array}{l}1 \\
(100.0)\end{array}$ & $1(0.8)$ & 0.167 & $\begin{array}{l}8.00 \\
(0.25- \\
259.50)\end{array}$ & - & $\begin{array}{l}1 \\
(100.0)\end{array}$ & $1(0.9)$ & 0.480 & $\begin{array}{l}3.23 \\
(0.10- \\
100.60)\end{array}$ \\
\hline No & $\begin{array}{l}22 \\
(18.5)\end{array}$ & $\begin{array}{l}97 \\
(81.5)\end{array}$ & $\begin{array}{l}119 \\
(99.2)\end{array}$ & & 1.00 & $7(5.9)$ & \begin{tabular}{|l}
112 \\
$(94.1)$
\end{tabular} & $\begin{array}{l}119 \\
(99.2)\end{array}$ & & 1.00 & \begin{tabular}{|l}
15 \\
$(13.4)$
\end{tabular} & $\begin{array}{l}97 \\
(86.6)\end{array}$ & $112(99.1)$ & & 1.00 \\
\hline \multicolumn{16}{|c|}{ NB $\ddagger$ weight/GA§ } \\
\hline SGA\| & - & $\begin{array}{l}6 \\
(100.0)\end{array}$ & $6(5.0)$ & 0.073 & $\begin{array}{l}0.42 \\
(0.02- \\
7.81) \\
\end{array}$ & - & $\begin{array}{l}6 \\
(100.0)\end{array}$ & $6(5.0)$ & 0.640 & $\begin{array}{l}2.04 \\
(0.10- \\
43.25) \\
\end{array}$ & - & $\begin{array}{l}6 \\
(100.0)\end{array}$ & $6(5.3)$ & 0.682 & $\begin{array}{l}0.55 \\
(0.03- \\
10.34) \\
\end{array}$ \\
\hline AGA & $\begin{array}{l}17 \\
(16.7) \\
\end{array}$ & $\begin{array}{l}85 \\
(83.3)\end{array}$ & $\begin{array}{l}102 \\
(85.0)\end{array}$ & & 1.00 & $4(3.9)$ & $\begin{array}{l}98 \\
(96.1)\end{array}$ & $\begin{array}{l}102 \\
(85.0)\end{array}$ & & 1.00 & $\begin{array}{l}13 \\
(13.3)\end{array}$ & $\begin{array}{l}85 \\
(86.7)\end{array}$ & $98(86.7)$ & & 1.00 \\
\hline$L_{G} A^{* *}$ & $5(41.7)$ & $7(58.3)$ & \begin{tabular}{|l}
12 \\
$(10.0)$ \\
\end{tabular} & 0.038 & $\begin{array}{l}3.57(1.01- \\
12.59)\end{array}$ & $3(25.0)$ & $9(75.0)$ & \begin{tabular}{|l}
12 \\
$(10.0)$ \\
\end{tabular} & 0.004 & $\begin{array}{l}8.17(1.58- \\
42.32)\end{array}$ & $2(22.2)$ & $7(77.8)$ & $9(8.0)$ & 0.459 & $\begin{array}{l}1.87(0.35- \\
9.99)\end{array}$ \\
\hline \multicolumn{16}{|l|}{ FAC†† } \\
\hline $\begin{array}{l}\text { Percentile } \\
<5\end{array}$ & $\begin{array}{l}14 \\
(16.3)\end{array}$ & $\begin{array}{l}72 \\
(83.7)\end{array}$ & $\begin{array}{l}86 \\
(71.7)\end{array}$ & 0.319 & \begin{tabular}{|l|}
0.61 \\
$(0.23-$ \\
$1.62)$ \\
\end{tabular} & $3(3.5)$ & $\begin{array}{l}83 \\
(96.5)\end{array}$ & \begin{tabular}{|l|}
86 \\
$(71.7)$
\end{tabular} & 0.073 & \begin{tabular}{|l|}
0.26 \\
$(0.06-$ \\
$1.24)$ \\
\end{tabular} & $\begin{array}{l}11 \\
(12.8)\end{array}$ & \begin{tabular}{|l|}
72 \\
$(87.2)$
\end{tabular} & $83(73.4)$ & 0.941 & \begin{tabular}{|l|}
0.96 \\
$(0.28-$ \\
$3.27)$ \\
\end{tabular} \\
\hline $\begin{array}{l}\text { Percentile } \\
\text { 5-95 }\end{array}$ & $8(24.2)$ & \begin{tabular}{|l}
25 \\
$(75.8)$ \\
\end{tabular} & $\begin{array}{l}33 \\
(27.5)\end{array}$ & & 1.00 & $4(12.1)$ & $\begin{array}{l}29 \\
(87.9)\end{array}$ & \begin{tabular}{|l|}
33 \\
$(27.5)$ \\
\end{tabular} & & 1.00 & $4(12.1)$ & $\begin{array}{l}25 \\
(87.9) \\
\end{array}$ & $29(25.7)$ & & 1.00 \\
\hline $\begin{array}{l}\text { Percentile } \\
>95\end{array}$ & - & $\begin{array}{l}1 \\
(100.0)\end{array}$ & $1(0.8)$ & 0.801 & $\begin{array}{l}1.56 \\
(0.05- \\
51.06) \\
\end{array}$ & - & $\begin{array}{l}1 \\
(100.0)\end{array}$ & $1(0.8)$ & 0.451 & $\begin{array}{l}3.63(0.11- \\
126.40)\end{array}$ & - & $\begin{array}{l}1 \\
(100.0)\end{array}$ & $1(0.9)$ & 0.511 & $\begin{array}{l}3.13 \\
(0.09- \\
109.30)\end{array}$ \\
\hline \multicolumn{16}{|c|}{ Type of delivery } \\
\hline Vaginal & $9(13.6)$ & $\begin{array}{l}57 \\
(86.4) \\
\end{array}$ & $\begin{array}{l}66 \\
(55.0) \\
\end{array}$ & & 1.00 & $2(3.0)$ & $\begin{array}{l}64 \\
(97.0)\end{array}$ & $\begin{array}{l}66 \\
(55.0) \\
\end{array}$ & & 1.00 & $7(10.9)$ & \begin{tabular}{|l|}
57 \\
$(89.1)$ \\
\end{tabular} & $64(56.6)$ & & 1.00 \\
\hline Cesarean & $\begin{array}{l}13 \\
(24.1)\end{array}$ & $\begin{array}{l}41 \\
(75.9)\end{array}$ & $\begin{array}{l}54 \\
(45.0)\end{array}$ & 0,142 & \begin{tabular}{|l|}
2.01 \\
$(0.78-$ \\
$5.14)$ \\
\end{tabular} & $5(9.3)$ & $\begin{array}{l}49 \\
(90.7)\end{array}$ & $\begin{array}{l}54 \\
(45.0)\end{array}$ & 0.148 & $\begin{array}{l}3.27 \\
(0.61- \\
17.54)\end{array}$ & $8(16.3)$ & $\begin{array}{l}41 \\
(83.7)\end{array}$ & $49(43.4)$ & 0.403 & \begin{tabular}{|l|}
1.59 \\
$(0.53-$ \\
$4.73)$ \\
\end{tabular} \\
\hline
\end{tabular}

Elnternational Association of Diabetes and Pregnancy Study Groups, ¥American Diabetes Association, ${ }^{\star}$ Gestational Diabetes Mellitus, †Odds Ratio, $\ddagger$ Newborn, §Gestational Age, ॥|Small for Gestational Age, $\uparrow$ Appropriate for Gestational Age, ${ }^{\star \star}$ Large for Gestational Age, $† \dagger$ Fetal Abdominal Circumference 


\section{DISCUSSION}

One of the strengths of this study remains in the fact that its application occurred in a reference center of prenatal care, with a standard screening method for GDM, and accessible to a diverse population. However, there was no pattern regarding the origin of the test results because OGTT was analyzed at different laboratories.

A higher diagnostic of GDM was noted when criterion I (IADPSG/ADA) was used, as expected since its cut-off points are lower, and it needs only one abnormal measure. This result was also found in other international studies ${ }^{9,14,15,26-28}$. In the study by O'Sullivan et al. ${ }^{26}$ a GDM tracking was performed using criterion I and compared to the results of criterion II. They found a higher prevalence of diagnoses by the criterion of IADPSG, and also a combination of these diagnoses with an increased incidence of adverse maternal and neonatal outcomes. Jenum et al. ${ }^{28}$ performed a universal screening of pregnant women at 28 weeks and found a prevalence of GDM 2.4 times higher with criterion I when compared to criterion II.

The results of this study have shown there is a difference in the prevalence of GDM defined by these two different criteria. Criterion I increased the diagnoses of GDM by 2.21 times when compared to criterion II, similar to the studies ${ }^{\text {citedg, 14,15,26-28 }}$. This finding raises a question regarding the need for intervention in patients who would be diagnosed by criterion I but currently are not diagnosed as GDM by criterion II.

The outcome of macrosomia had low prevalence among the subjects of this study. However, when related to the diagnostic of GDM by both criteria, there was a statistical difference in patients who were diagnosed by criterion II $(\mathrm{p}=0.004)$. This finding is consistent with other international studies ${ }^{26,27}$. O'Sullivan et al. ${ }^{26}$ assessed the impacts of the new diagnostic criteria for GDM proposed by IADPSG, but there was no significant association with macrosomia. Wendland et al. ${ }^{29}$ conducted a systematic review of the association

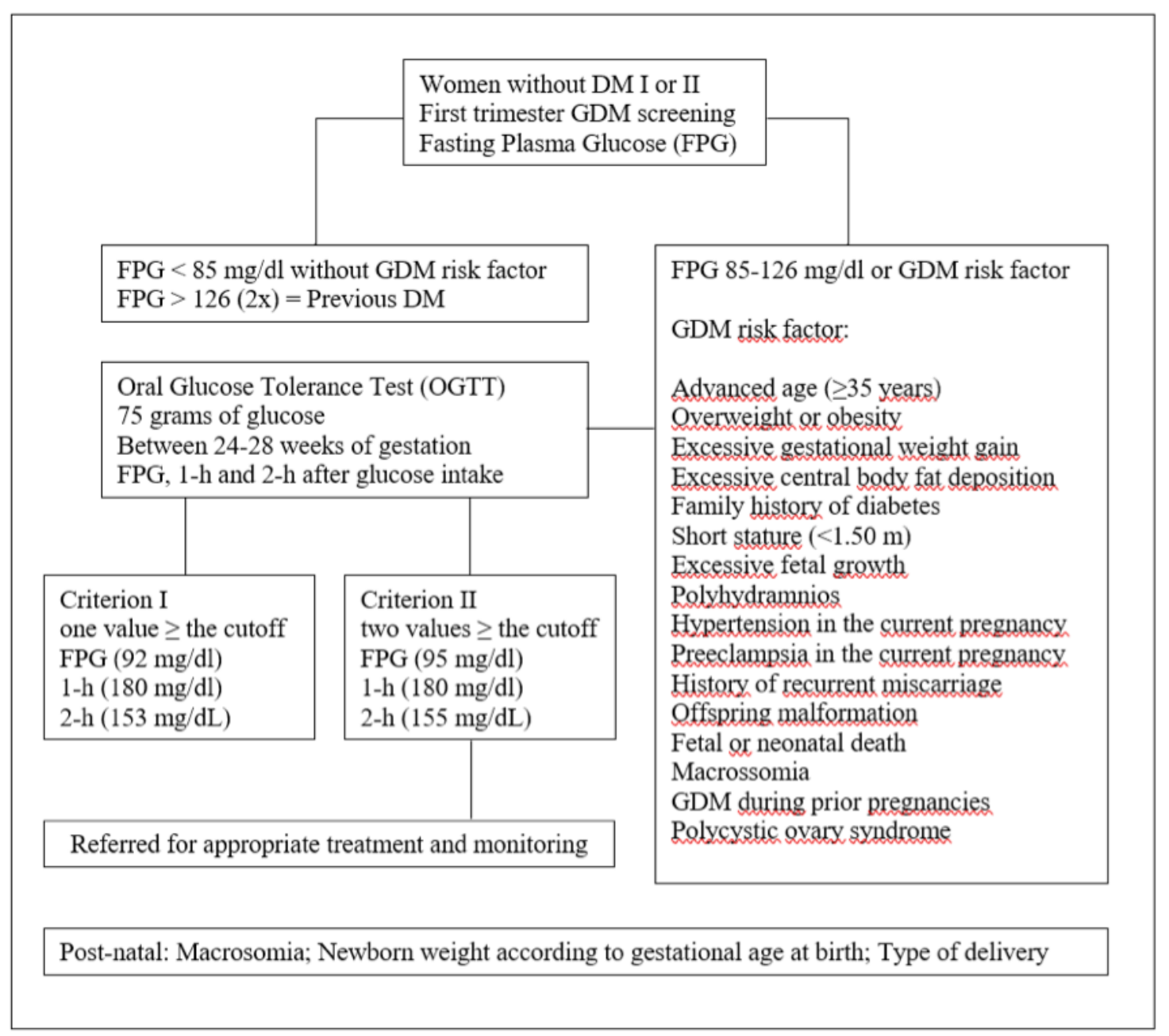

FIGURE 1. FLOW CHART OF PARTICIPANTS THROUGHOUT THE STUDY. 
between GDM and macrosomia. Results showed that patients diagnosed by criterion II were more likely to present macrosomia, and those diagnosed by criterion I but no longer by criterion II, were not associated with that outcome.

The research by O'Sullivan et al. ${ }^{26}$ reported a statistically significant association of GDM and polyhydramnios. The current study showed that regardless of the criteria used, there is no association between GDM and this obstetric feature, regardless of the criterion used.

The NB greater weight, according to gestational age, was significantly associated with the presence of GDM by criteria I and II. When the association between NB weight/GA and the diagnostic of GDM by criterion I and not by criterion II was analyzed, no difference was found. This result is also reported in other studies $^{2,26,29}$. One study reported an increased prevalence of large NB for their gestational age in pregnant women with GDM $^{26}$. Wendland et al..$^{29}$ and Koning et al. ${ }^{30}$ described the same association by both criteria.

FAC was not found to be statistically associated with the presence of GDM by both criterion I and II. Besides, this study did not identify any description with FAC above the 95th percentile, showing no relationship with GDM.

The predominant mode of delivery in this study was cesarean. According to O'Sullivan et al. ${ }^{26}$, the cesarean rate increased significantly in patients with GDM. Wendland et al. ${ }^{29}$ had shown that pregnant women diagnosed with GDM by criterion II presented an increased risk of cesarean delivery compared to pregnant women diagnosed by criterion I. The present analysis did not find any statistically relevant association between both criteria.

The strength of this research was the use of the same patients to evaluate different criteria. Thus, the results were elaborated on the same sample population, reducing the bias of group differences. Otherwise, it was limited to a restrict sample, even knowing that it might be inferred to other populations.

Criterion I of a $2 \mathrm{~h} 75 \mathrm{~g}$ OGTT increased the prevalence of GDM, but patients diagnosed by this criterion alone, which no longer were diagnosed by criterion II, did not present any outcomes. Therefore, patients diagnosed by criterion I, but not by criterion II, during pregnancy, could receive unnecessary interventions. These patients would undergo unnecessary diets or use hypoglycemic agents. The outcomes verified in patients by criterion I were the same as those of criterion II, regarding the idea that criterion II might possibly continue to be chosen as GDM screening protocol.

\section{Acknowledgment}

This study was partially financed by CAPES Financial Code 001.

Authors declare no conflicts of interest

\section{Authors' contributions}

Rodrigo Dias Nunes - Design, data collection, analysis, and interpretation of data, review, and approval of the final version of the article.

Mayara Eloisa Flôres - Design, data collection, analysis, and interpretation of data, review, and approval of the final version of the article.

Mayara Seemann - Analysis and interpretation of the data, review, and approval of the final version of the article.

Eliane Traebert - Analysis and interpretation of the data, review, and approval of the final version of the article.

Jefferson Traebert - Analysis and interpretation of the data, review, and approval of the final version of the article.

\section{RESUMO}

OBJETIVO: Avaliar dois critérios distintos, um ou dois valores de corte, do teste oral de tolerância à glicose com $75 \mathrm{~g}$ de glicose para o diagnóstico de diabetes mellitus gestacional. Métodos: Estudo transversal envolvendo 120 prontuários de gestantes que realizaram pré-natal em um ambulatório de uma universidade brasileira. Análise bivariada dos resultados obstétricos e perinatais foi realizada pelo teste do qui-quadrado. Resultados: Considerando o critério I, 12,5\% das pacientes foram diagnosticadas com diabetes mellitus gestacional. As pacientes apresentaram uma chance 3,57 maior de ter um feto grande para a idade gestacional $(p=0,038)$. Utilizando o critério II, o diabetes mellitus gestacional foi diagnosticado em $5,8 \%$ das pacientes. Mediante esse critério diagnóstico, a chance de macrossomia foi 7,73 vezes mais provável na presença de diabetes mellitus gestacional $(p=0,004)$ e a chance de um feto grande para a idade gestacional foi 8,17 vezes maior de ocorrer ( $p=0,004)$. Conclusões: Observou-se diferença na prevalência de diabetes melittus gestacional entre os dois critérios analisados, sendo que o novo critério proposto aumentou a prevalência.

PALAVRAS-CHAVE: Diabetes gestacional. Técnicas e procedimentos diagnósticos. Teste de tolerância à glicose. Assistência perinatal. 


\section{REFERENCES}

1. Sociedade Brasileira de Endocrinologia e Metabologia. Diabetes mellitus gestacional. Rev Assoc Med Bras. 2008;54(6):471-86.

2. HAPO Study Cooperative Research Group, Metzger BE, Lowe LP, Dyer AR, Trimble ER, Chaovarindr U, Coustan DR, et al. Hyperglycemia and adverse pregnancy outcomes. N Engl J Med. 2008;358(19):1991-2002.

3. Bider-Canfield Z, Martinez MP, Wang X, Yu W, Bautista MP, Brookey J, et al. Maternal obesity, gestational diabetes, breastfeeding and childhood overweight at age 2 years. Pediatr Obes. 2017;12(2):171-8.

4. Sudasinghe BH, Wijeyaratne CN, Ginige PS. Long and short-term outcomes of Gestational Diabetes Mellitus (GDM) among South Asian women: a community-based study. Diabetes Res Clin Pract. 2018;145:93-101.

5. Canadian Diabetes Association Clinical Practice Guidelines Expert Committee. Canadian Diabetes Association 2008: clinical practice guidelines for the prevention and management of diabetes in Canada. Can | Diabetes. 2008;32(suppl 1):S1-S201.

6. Huhn EA, Massaro N, Streckeisen S, Manegold-Brauer G, Schoetzau A Schulzke SM, et al. Fourfold increase in prevalence of gestational diabetes mellitus after adoption of the new International Association of Diabetes and Pregnancy Study Groups (IADPSG) criteria. J Perinat Med. 2017;45(3):359-66

7. Meltzer S), Snyder J, Penrod JR, Nudi M, Morin L. Gestational diabetes mellitus screening and diagnosis: a prospective randomised controlled trial comparing costs of one-step and two-step methods. BJOG. 2010;117(4):407-15.

8. Chiefari E, Arcidiacono B, Foti D, Brunetti A. Gestational diabetes mellitus: an updated overview. J Endocrinol Invest. 2017;40(9):899-909.

9. Mack LR, Tomich PG. Gestational diabetes: diagnosis, classification, and clinical care. Obstet Gynecol Clin North Am. 2017;44(2):207-17.

10. Horvath K, Koch K, Jeitler K, Matyas E, Bender R, Bastian H, et al. Effects of treatment in women with gestational diabetes mellitus: systematic review and meta-analysis. BMJ. 2010;340:c1395.

11. Immanuel J, Simmons D. Screening and treatment for early-onset gestational diabetes mellitus: a systematic review and meta-analysis. Curr Diab Rep. 2017;17(11):115.

12. Gillman MW, Oakey H, Baghurst PA, Volkmer RE, Robinson JS, Crowther CA. Effect of treatment of gestational diabetes mellitus on obesity in the next generation. Diabetes Care. 2010;33(5):964-8.

13. American Diabetes Association. 2. Classification and diagnosis of diabetes: standards of medical care in diabetes-2018. Diabetes Care. 2018;41(Suppl 1):S13-S27.

14. Agarwal MM, Dhatt GS, Shah SM. Gestational diabetes mellitus: simplifying the international association of diabetes and pregnancy diagnostic algorithm using fasting plasma glucose. Diabetes Care. 2010;33(9):2018-20.

15. International Association of Diabetes and Pregnancy Study Groups Consensus Panel, Metzger BE, Gabbe SG, Persson B, Buchanan TA, Catalano PA, Damm $P$, et al. International association of diabetes and pregnancy study groups recommendations on the diagnosis and classification of hyperglycemia in pregnancy. Diabetes Care. 2010;33(3):676-82.

16. Coustan DR, Lowe LP, Metzger BE, Dyer AR; International Association of Diabetes and Pregnancy Study Groups. The Hyperglycemia and Adverse
Pregnancy Outcome (HAPO) study: paving the way for new diagnostic criteria for gestational diabetes mellitus. Am J Obstet Gynecol. 2010;202(6):654. e1-6.

17. Lu Y, Zhang J, Lu X, Xi W, Li Z. Secular trends of macrosomia in southeast China, 1994-2005. BMC Public Health. 2011;11:818.

18. Diabetes Canada Clinical Practice Guidelines Expert Committee, Feig DS, Berger H, Donovan L, Godbout A, Kader T, Keely E, et al. Diabetes and pregnancy. Can J Diabetes. 2018;42(Suppl 1):S255-82.

19. Committee on Practice Bulletins-Obstetrics. ACOG Practice Bulletin No. 190: Gestational Diabetes Mellitus. Obstet Gynecol. 2018;131(2):e49-e64.

20. National Institutes of Health consensus development conference statement: diagnosing gestational diabetes mellitus, March 4-6, 2013. Obstet Gynecol. 2013;122(2 Pt 1):358-69.

21. Carracher $\mathrm{AM}$, Marathe $\mathrm{PH}$, Close $\mathrm{KL}$. International Diabetes Federation 2017. J Diabetes. 2018;10(5):353-6.

22. Moyer VA; U.S. Preventive Services Task Force. Screening for gestational diabetes mellitus: U.S. Preventive Services Task Force recommendation statement. Ann Intern Med. 2014;160:414-20.

23. Soares TS, Andreolla AP, Miranda CA, Klöppel E, Rodrigues LS, MoraesSouza RQ, et al Effect of the induction of transgenerational obesity on maternal-fetal parameters. Syst Biol Reprod Med. 2018;64(1):51-9.

24. El Khouly NI, Elkelani OA, Saleh SA. Amniotic fluid index and estimated fetal weight for prediction of fetal macrosomia: a prospective observational study. J Matern Fetal Neonatal Med. 2017;30(16):1948-52.

25. Gibson KS, Stetzer B, Catalano PM, Myers SA. Comparison of 2- and 3-dimensional sonography for estimation of birth weight and neonatal adiposity in the setting of suspected fetal macrosomia. / Ultrasound Med. 2016;35(6):1123-9.

26. O'Sullivan EP, Avalos G, O'Reilly M, Dennedy MC, Gaffney G, Dunne F; Atlantic DIP collaborators. Atlantic Diabetes in Pregnancy (DIP): the prevalence and outcomes of gestational diabetes mellitus using new diagnostic criteria. Diabetologia. 2011;54(7):1670-5.

27. HAPO Study Cooperative Research Group. Hyperglycemia and Adverse Pregnancy Outcome (HAPO) Study: associations with neonatal anthropometrics. Diabetes. 2009;58(2):453-9.

28. Jenum AK, Mørkrid K, Sletner L, Vangen S, Torper JL, Nakstad B, et al. Impact of ethnicity on gestational diabetes identified with the WHO and the modified International Association of Diabetes and Pregnancy Study Groups criteria: a population-based cohort study. Eur J Endocrinol. 2012;166(2):317-24.

29. Wendland EM, Torloni MR, Falavigna M, Trujillo |, Dode MA, Campos MA, et al. Gestational diabetes and pregnancy outcomes: a systematic review of the World Health Organization (WHO) and the International Association of Diabetes in Pregnancy Study Groups (IADPSG) diagnostic criteria. BMC Pregnancy Childbirth. 2012;12:23.

30. Koning SH, van Zanden ||, Hoogenberg K, Lutgers HL, Klomp AW, Korteweg F), et al. New diagnostic criteria for gestational diabetes mellitus and their impact on the number of diagnoses and pregnancy outcomes. Diabetologia. 2018;61(4):800-9. 